\title{
Erratum to: Diagnostic Differentiation of Autism Spectrum Disorders and Pragmatic Language Impairment
}

\author{
Lisa M. Reisinger · Kim M. Cornish • \\ Éric Fombonne
}

Published online: 2 April 2011

(C) Springer Science+Business Media, LLC 2011

\section{Erratum to: J Autism Dev Disord \\ DOI 10.1007/s10803-011-1196-y}

Correction is needed to the sentence that begins with the words "Participants met the criteria..." in the Qualification measure CCC-2 subsection of the "Assessment Instruments" section of this article.

The following is the sentence as it should read:
Participants met the criteria for PLI on the CCC-2 if they achieved either a social interaction deviance composite (SIDC) $\leq-15$, indicating a severe pragmatic skills delay or an SIDC $<0$ and a composite score $<55$ on the general communication composite (GCC) of this measure, indicating an uneven profile of disproportionately impaired pragmatic skills in relation to their structural language impairments (Norbury et al. 2004).

The online version of the original article can be found under doi:10.1007/s10803-011-1196-y.

L. M. Reisinger $(\bowtie) \cdot$ K. M. Cornish

Department of Educational and Counselling Psychology,

McGill University, Montreal, Canada

e-mail: lisa.reisinger@mail.mcgill.ca

L. M. Reisinger · É. Fombonne

Autism Spectrum Disorders Program, Montreal Children's

Hospital, Montreal, Canada

K. M. Cornish

Centre for Developmental Psychiatry and Psychology,

Faculty of Medicine, Nursing and Health Sciences,

Monash University, Melbourne, Australia

É. Fombonne

Department of Psychiatry, McGill University,

Montreal, QC, Canada 